\title{
The timed walk test as a measure of severity and survival in idiopathic pulmonary fibrosis
}

\author{
T.S. Hallstrand*, L.J. Boitano*, W.C. Johnson\#, C.A. Spada*, J.G. Hayes* and G. Raghu*
}

\begin{abstract}
Idiopathic pulmonary fibrosis (IPF) is a relentlessly progressive disease with a median survival of $\sim 3$ yrs. Measurements of airflow and lung volumes at rest are generally used to monitor the clinical course in this disorder. This study was designed to determine if a modified version of the 6-min walk test, called the timed walk test, accurately characterises disease severity and survival in IPF.

The study population consisted of 28 patients with well-characterised progressive IPF. The timed walk test and concurrent measures of disease severity were assessed at baseline. Participants were prospectively followed for $\geqslant 4$ yrs to determine the relationship between parameters of the timed walk test and survival.

There were strong correlations between the end-exercise saturation and walk-velocity parameters of the timed walk test and diffusing capacity, and arterial oxygen tension at rest. In univariate Cox proportional-hazards models, end-exercise saturation, change in saturation with exercise, walk distance and walk velocity were associated with survival. In unadjusted logistic regression models, odds of death at 2 yrs were associated with the same parameters.

In conclusion, the timed walk test relates to disease severity and long-term outcome in progressive idiopathic pulmonary fibrosis.
\end{abstract}

KEYWORDS: Idiopathic pulmonary fibrosis, interstitial lung disease, pulmonary function, survival, walk test

diopathic pulmonary fibrosis (IPF) is a chronic progressive interstitial lung disease (ILD) of unknown cause, resulting in severe morbidity and death due to progressive respiratory failure [1], usually within 3-5 yrs [2-5]. Prognostic factors that have been variably associated with survival include age [6], smoking status [7], sex [8], resting pulmonary function [9], histopathology score [7], fibrotic score based on high-resolution computed tomography [10, 11], and initial response to treatment with corticosteroids [10]. A composite score of clinical, radiographical and physiological variables has been associated with survival in IPF [12]. Survival is the most important treatment outcome in IPF, but requires large numbers of patients with this rare disease for long periods (i.e. 3-5 yrs) of prospective follow-up. A measurement of disease and functional status that can serve as a surrogate outcome measurement to accurately reflect the risk of progression to death in IPF is needed.

A practical and simple measurement of functional status that is widely used as a clinical tool and outcome measure of patients with heart [13], obstructive lung disease [14], vascular [15], and neuromuscular disease [16] is the 6-min walk test
(6MWT). However, the physiological abnormalities associated with disease severity and progression in IPF are not fully characterised by the distance of the $6 \mathrm{MWT}[7,9,12]$. This was illustrated recently in the study by LAMA et al. [17], which showed that, in a subgroup of patients with IPF without resting hypoxaemia, the 6MWT distance was not associated with survival [17]. Cardiopulmonary exercise tests have shown that changes in arterial saturation and exercise performance are related to survival in IPF, leading to the hypothesis in the current study that similar parameters assessed during a self-paced walk test would be associated with survival. Therefore, a modified version of the $6 \mathrm{MWT}$, the timed walk test (TWT), was developed as a clinical tool and outcome measurement in IPF. The TWT has three stopping criteria so that continuous walk velocity can be assessed and to incorporate change in oxyhaemoglobin saturation during continuous exercise. To make the test applicable to patients with a range of disease severity and to reduce the influence of hypoxaemia on walk velocity $[18,19]$, the TWT was conducted in room air in patients with a baseline saturation $>88 \%$ and on supplemental
AFFILIATIONS

*Dept of Medicine, Division of Pulmonary and Critical Care Medicine, and \#Dept of Biostatistics, University of Washington, Seattle,

WA, USA.

CORRESPONDENCE

G. Raghu

Chest Clinic

Interstitial Lung Disease

Sarcoid and Pulmonary Fibrosis

Program

University of Washington Medical

Center

Box 356522

BB-1253 HSC

1959 NE Pacific Street

Seattle,

WA 98195-6522

USA

Fax: 12066858673

E-mail: graghu@u.washington.edu

Received:

December 112003

Accepted after revision:

August 302004 
oxygen if baseline saturation was $<88 \%$. In this study, the relationship between the TWT and concurrent measures of disease severity conventionally used in IPF was evaluated. Participants were prospectively followed for $\geqslant 4$ yrs to determine the relationship between parameters of the TWT and survival.

\section{METHODS}

\section{Study population}

A prospective study of consecutive new referrals for further management of IPF (referred to the Interstitial Lung Disease Clinic, University of Washington Medical Center, Seattle, WA, USA, and for further evaluation and management in the Interstitial Lung Disease/Sarcoid/Pulmonary Fibrosis Program at the University of Washington under the direction of G. Raghu) was initiated between 1996 and 1998. Patients were included in this study if they consented to the study and met the diagnostic criteria for IPF. The diagnosis of IPF was ascertained by typical clinical, radiographical, nondiagnostic transbronchial biopsy, and physiological features consistent with IPF; surgical lung biopsy demonstrating histological features of usual interstitial pneumonia was accepted for the diagnosis of IPF in patients not meeting the major and minor clinical criteria [1, 20]. Persons with collagen vascular disease, occupational lung disease, sarcoid, hypersensitivity pneumonitis and other idiopathic interstitial pneumonias were excluded [1, 21]. Patients with concurrent emphysema were excluded based on elevated residual volume of $\geqslant 120 \%$ and forced expiratory volume in one second (FEV1)/forced vital capacity (FVC) ratio of $\leqslant 0.60$. Patients with IPF who were entered into this study had progressive symptomatic and/or physiological deterioration [1], despite treatment with prednisone with or without immunosuppressives. The University of Washington Human Subjects Review Committee approved the study, and each participant gave written informed consent.

\section{Timed walk test}

A designated respiratory therapist (L.J. Boitano) conducted the TWT on a 30-m-long level course marked in 1.5-m increments. Oxygen saturation was recorded continuously by pulse oximetry at rest for $5 \mathrm{~min}$ prior to the test, throughout the TWT and immediately after the test. Patients with resting room air saturation $>88 \%$ had an initial walk test in room air and were subsequently asked to perform a second test on $2 \mathrm{~L}$ of oxygen. Patients with resting saturation $\leqslant 88 \%$ were tested only on $2 \mathrm{~L}$ of oxygen after a 5 -min period of supplemental oxygen at rest. During the TWT, patients were instructed to walk at a pace comfortable to them until they became too fatigued, up to a maximum of $6 \mathrm{~min}$. The respiratory therapist stopped the test if the patient demonstrated signs of overt fatigue and/or asked to stop, or the saturation dropped to $<80 \%$. Although the test was stopped when saturation reached $80 \%$, the lowest saturation was recorded if the saturation continued to decline. The distance, time and saturation were recorded at the end of the test. The primary parameters of the TWT were the end-exercise saturation, change in saturation from baseline and walk velocity. Secondary parameters were walk distance and walk time.

\section{Pulmonary function testing}

Spirometry, plethysmographic lung volumes and diffusing capacity for carbon monoxide $(\mathrm{DL}, \mathrm{CO})$ were performed within $24 \mathrm{~h}$ of the TWT, according to American Thoracic Society standards [22]. Arterial blood gases were obtained after $5 \mathrm{~min}$ of inactivity. The alveolar-arterial oxygen tension $\left(P \mathrm{~A}-\mathrm{a}, \mathrm{O}_{2}\right)$ difference was calculated by the alveolar gas equation [23].

\section{Statistical analysis}

Relationships between parameters of the TWT and pulmonary function were assessed with Spearman rank correlation coefficients. Least squares linear regression was used to further delineate the association between DL,CO and the TWT parameters. An intraclass correlation coefficient was used to assess the repeatability of the TWT.

Survival time was measured in days from enrolment until death or censoring. Patients were censored at the end of the follow-up period or if they underwent lung transplantation. Univariate Cox proportional-hazards models assessed the relative hazard corresponding to overall mortality for each TWT parameter. Cox proportional-hazards models were subsequently adjusted for supplemental oxygen to assess its effect on each TWT parameter in predicting survival. The effects of other demographic and baseline variables on TWT parameter estimates of survival were also explored using multivariate Cox proportional-hazards models. Kaplan-Meier estimates of survival were used to illustrate the findings of the Cox model. Logistic regression models of TWT parameters predicting 2-yr survival were used to corroborate findings of the survival analyses.

\section{RESULTS}

\section{Study participants}

A total of 28 consecutive patients with IPF [1] were enrolled in the study (table 1 ). Disease severity ranged from FVC $\geqslant 70 \%$ pred in eight patients and $\leqslant 40 \%$ pred in five. All patients had progressive disease based on symptoms or pulmonary function tests, despite treatment with prednisone with or without azathioprine [1].

\section{Characteristics of the timed walk test}

At entry, nine of the 28 participants had resting oxyhaemoglobin saturations $\leqslant 88 \%$ and, therefore, were only tested on $2 \mathrm{~L}$ of supplemental oxygen. Six of these nine participants who were tested on supplemental oxygen stopped prior to $6 \mathrm{~min}$ because arterial oxygen saturation measured by pulse oximetry $\left(\mathrm{SP}, \mathrm{O}_{2}\right)$ reached $80 \%$. Of the 19 patients tested in room air, five were stopped prior to $6 \mathrm{~min}$ of walking due to $\mathrm{SP}, \mathrm{O}_{2}$ that reached $80 \%$. Three patients with resting saturations $>88 \%$ declined the additional test on $2 \mathrm{~L}$ of oxygen. Four of the five that were stopped prior to $6 \mathrm{~min}$ during the room air test completed 6 min on oxygen without desaturating to $80 \%$. In the 16 patients tested on both room air and oxygen, walk distance increased from $271.2 \mathrm{~m}$ to $345.6 \mathrm{~m}$ when oxygen was administered during the test. The impact of supplemental oxygen and the reproducibility of the TWT were assessed in the subgroup that was tested both on and off oxygen. Walk distance increased by $27.5 \%$, whilst walk velocity $(17.8 \%)$ and change in saturation (19.3\%) were less susceptible to the effect of supplemental oxygen. The intraclass correlation coefficient was $0.76(p=0.017)$ for walk distance, $0.96(p<0.0001)$ for walk 


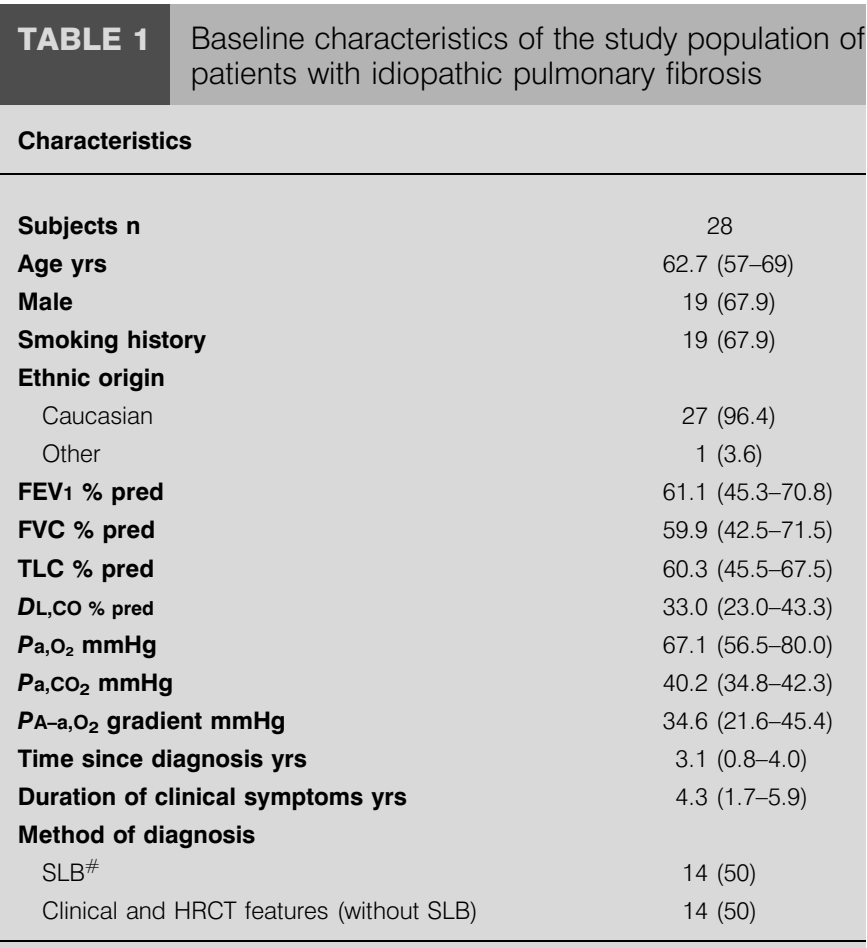

Data are presented as $n$, mean (interquartile range) and $n(\%)$. FEV 1 : forced expiratory volume in one second; \% pred: \% predicted; FVC: forced vital capacity; TLC: total lung capacity; $D \mathrm{~L}, \mathrm{CO}$ : diffusing capacity for carbon monoxide, corrected to haemoglobin; $\mathrm{Pa}, \mathrm{O}_{2}$ : arterial oxygen tension; $\mathrm{Pa}_{1} \mathrm{CO}_{2}$ : arterial carbon dioxide tension; $\mathrm{PA}-\mathrm{a}, \mathrm{O}_{2}$ : alveolar-arterial oxygen tension; SLB: surgical lung biopsy; HRCT: high-resolution computed tomography. ${ }^{\#}$ : in addition to clinical and HRCT features. $1 \mathrm{kPa}=0.133 \mathrm{mmHg}$.

velocity and $0.59(p=0.047)$ for change in saturation, despite the addition of oxygen between the two tests.

\section{Association of the timed walk test with pulmonary function}

To assess the relationship between the TWT and spirometry, lung volumes, DL,CO and arterial blood-gas parameters, the results of the TWT in room air or on $2 \mathrm{~L}$ of oxygen (according to the pre-specified criteria) were used. There were no correlations between the parameters of the TWT and the FVC, FEV1, total lung capacity and arterial carbon dioxide tension. There were strong correlations between $D \mathrm{~L}, \mathrm{CO}$, resting arterial oxygen tension $\left(\mathrm{Pa}_{\mathrm{a}} \mathrm{O}_{2}\right)$ and $\mathrm{PA}-\mathrm{a}, \mathrm{O}_{2}$ difference, and endexercise saturation, walk-distance and walk-velocity parameters of the TWT (table 2). Using a linear regression model, it was found that the relationship between $D \mathrm{~L}, \mathrm{CO}$ and the endexercise saturation parameter of the TWT predicts a decrease of $11.8 \%$ pred $D \mathrm{~L}, \mathrm{CO}$ for each $5 \%$ decrement in end-exercise saturation (95\% confidence interval (CI): $7.75-15.85)$, or a $36 \%$ difference in $D \mathrm{~L}, \mathrm{CO}$ relative to the mean value in this population (fig. 1a). Addition of the type of test (i.e. room air or oxygen), age, sex, FVC, time from diagnosis and time from onset of symptoms to the regression model did not alter this relationship. A linear regression model showed that the relationship between $D \mathrm{~L}, \mathrm{CO}$ and the walk-velocity parameter of the TWT predicts a decrease of $25.35 \%$ pred DL,CO for each $1 \mathrm{~m} \cdot \mathrm{s}^{-1}$ decrement in walk velocity (95\% CI: 14.64-36.06; fig. 1b).

\section{Association of the timed walk test with survival}

Patients were prospectively followed from enrolment for a median (range) of 5.4 yrs (4.3-6.2). Whilst 19 out of $28(67.9 \%)$ patients died within 2 yrs from the time of the baseline TWT, 22 out of $28(78.6 \%)$ died over the entire follow-up period at an average (range) of 1.2 yrs (0.2-3.0) from enrolment. During the study period, five patients underwent single-lung transplant at an average of $1.5 \mathrm{yrs}$ (1.0-2.4) from enrolment and were censored in the analysis at the time of transplantation. In univariate Cox proportional-hazards models of survival, endexercise saturation, change in saturation with exercise, walk distance and walk velocity were associated with mortality (table 3). The DL,CO, which was highly correlated with parameters of the TWT, was also associated with survival. Addition of the use of supplemental oxygen during the TWT to the proportional-hazards model did not influence the estimate of relative hazard. Multivariate proportional-hazards models were created for parameters of the TWT (table 3). The addition of the use of supplemental oxygen, age, sex, FVC \% pred and duration of symptoms did not appreciably alter the univariate estimates of the associations between parameters of the TWT and survival.

Kaplan-Meier survival analysis grouped according to tertiles of walk velocity showed that the median survival times were reduced according to the strata of walk velocity (fig. 2a; table $4 ; \mathrm{p}=0.019, \log$ rank test). Grouping according to tertiles of change in saturation with exercise demonstrated reduced survival according to strata by Kaplan-Meier survival analysis (fig. $2 \mathrm{~b}$; table $5 ; \mathrm{p}=0.024$, log rank test).

TABLE 2 Associations between pulmonary function and parameters of the timed walk test

\begin{tabular}{|c|c|c|c|c|c|c|}
\hline \multirow[t]{2}{*}{ Variable } & \multicolumn{2}{|c|}{$D L, C O$} & \multicolumn{2}{|c|}{$\mathrm{Pa}, \mathrm{O}_{2}$} & \multicolumn{2}{|c|}{$P A-a, O_{2}$ difference } \\
\hline & $\mathbf{r}$ & p-value & $\mathbf{r}$ & $\mathrm{p}$-value & $\mathbf{r}$ & p-value \\
\hline Change in $\mathrm{SP}, \mathrm{O}_{2}$ with exercise & -0.63 & 0.001 & -0.33 & 0.129 & 0.33 & 0.129 \\
\hline Walk distance & 0.77 & $<0.001$ & 0.67 & $<0.001$ & -0.67 & $<0.001$ \\
\hline Walk velocity & 0.73 & $<0.001$ & 0.73 & $<0.001$ & -0.70 & $<0.001$ \\
\hline
\end{tabular}

$\mathrm{DL}, \mathrm{CO}$ : diffusing capacity for carbon monoxide; $\mathrm{Pa}_{1} \mathrm{O}_{2}$ : arterial oxygen tension; $\mathrm{PA}-\mathrm{a}, \mathrm{O}_{2}$ : alveolar-arterial oxygen tension; $\mathrm{SP}, \mathrm{O}_{2}$ : arterial oxygen saturation measured by pulse oximetry. 

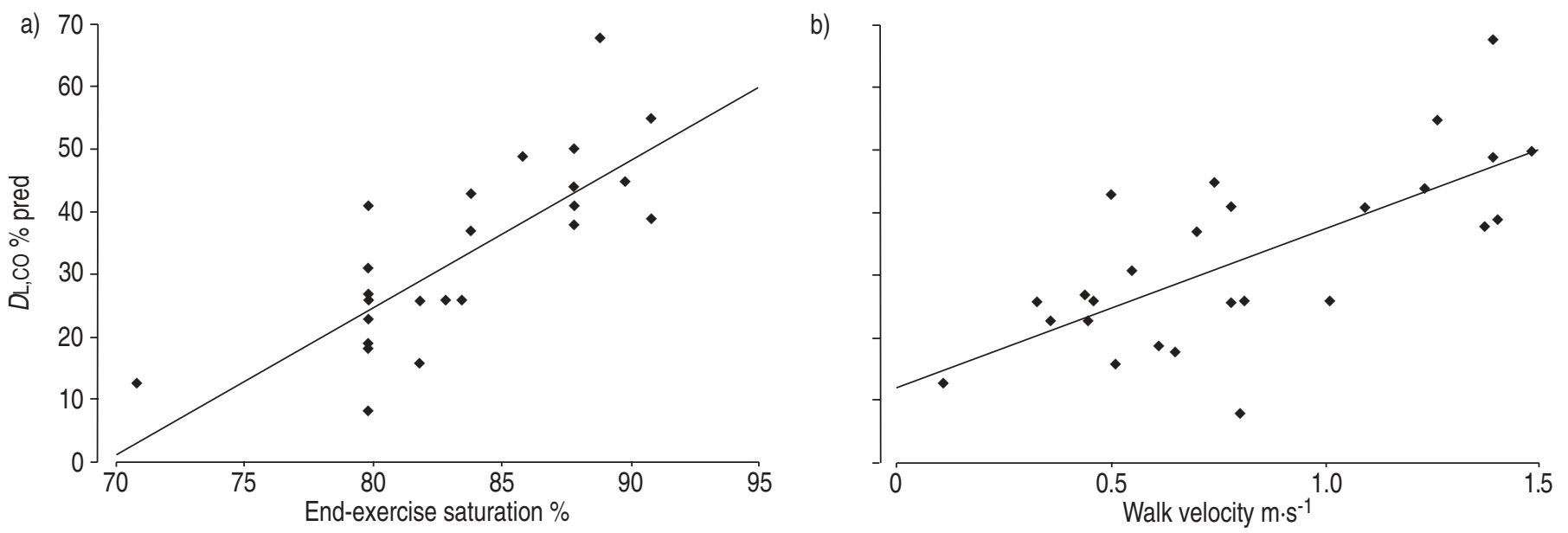

FIGURE 1. Relationships between diffusing capacity for carbon monoxide $(D\llcorner, \mathrm{CO})$ and a) end-exercise saturation and b) walk-velocity parameters of the timed walk test (TWT) in a population ( $n=26$ ) of patients with advanced idiopathic pulmonary fibrosis. Least squares linear regression was used to describe the relationship between $D L, C O$ and the TWT parameters (a) $B=2.36,95 \%$ confidence interval ( $\mathrm{Cl}$ ): 1.55-3.17; b) $\mathrm{B}=25.35,95 \% \mathrm{Cl}$ : 14.64-36.06).

To corroborate the findings of the proportional-hazards model, the associations between parameters of the TWT and 2-yr survival were assessed by logistic regression. According to an unadjusted logistic regression model, odds of death after 2 yrs were reduced with incremental improvements in end-exercise saturation, change in saturation with exercise, walk distance and walk velocity (table 6). $\mathrm{DL}, \mathrm{CO}$ and resting $\mathrm{Pa}_{1} \mathrm{O}_{2}$ were also associated with death after 2 yrs.

\section{DISCUSSION}

IPF is a fatal disease with no known effective therapy. Clinicians need to provide accurate prognostic information to patients with IPF. In this study, the current authors describe a modified version of the $6 \mathrm{MWT}$, the TWT, which is designed to capture information about the physiological limitations of patients with IPF with a broad range of disease severity. The TWT is a simple clinical tool that can be readily applied to clinical practice and incorporates information about haemoglobin saturation at rest and with exertion, characterises continuous walk velocity, and has a uniform approach to the use of supplemental oxygen during the test that is based on resting saturation. This is the first study to characterise the TWT in a well-defined population of patients with established IPF, showing that the TWT is associated with disease severity, gas exchange and long-term survival.

The 6MWT is widely used and provides important prognostic information in several chronic cardiopulmonary disease states [13-16]. The primary outcome measurement of the 6MWT is the distance walked during a period of $6 \mathrm{~min}$, which may include periods of rest. In contrast, the TWT assesses the

TABLE 3 Results of univariate and multivariate Cox proportional-hazards models relating parameters of the timed walk test and pulmonary function to mortality

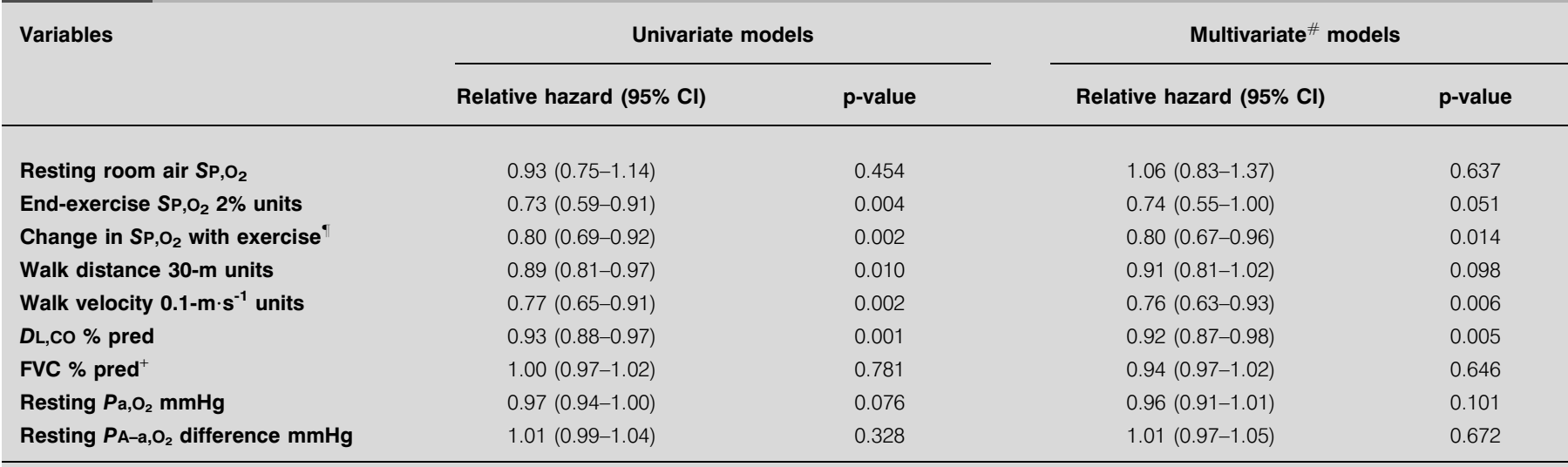

$\mathrm{Cl}$ : confidence interval; $\mathrm{SP}, \mathrm{O}_{2}$ : arterial oxygen saturation measured by pulse oximetry; $\mathrm{DL}, \mathrm{CO}$ : diffusing capacity for carbon monoxide; \% pred: \% predicted; FVC: forced

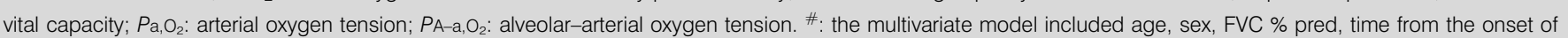
symptoms and supplemental oxygen administration during the test; " : for consistency, change in saturation was entered as a negative change such that a lesser degree of desaturation would be associated with reduced mortality; ${ }^{+}$: the multivariate model excluded FVC as a covariate. $1 \mathrm{kPa}=0.133 \mathrm{mmHg}$ 


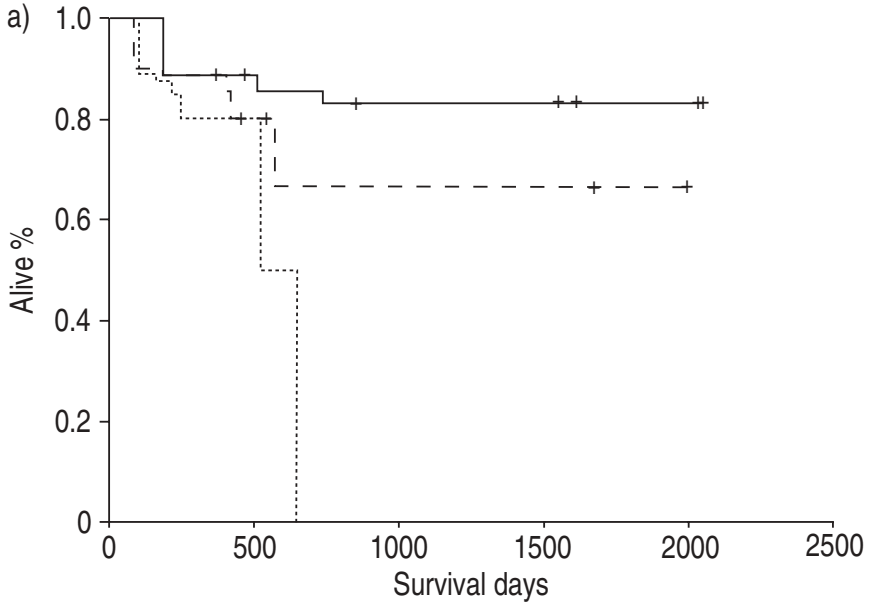

b)

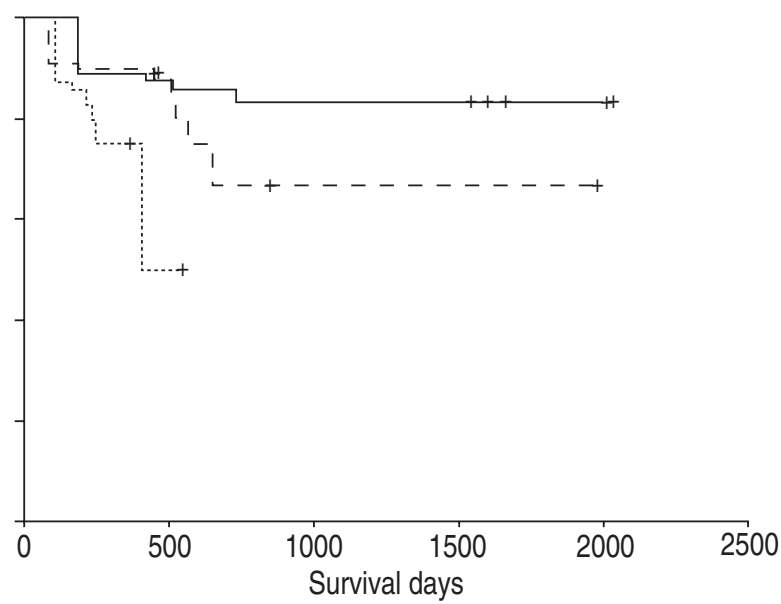

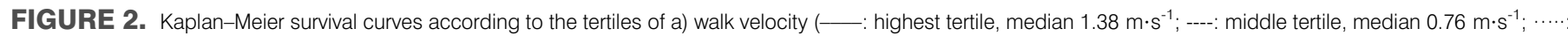

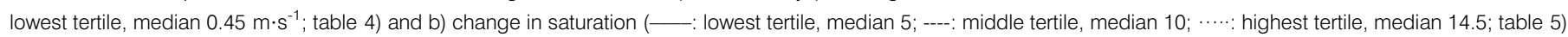
parameters of the timed walk test. Survival curves were compared with the log rank statistic (a) $p=0.019 ; b) p=0.024)$. +: censored.

\begin{tabular}{lccccc} 
TABLE 4 & $\begin{array}{l}\text { Numbers at risk according to the tertiles of the } \\
\text { walk-velocity parameter at different survival time } \\
\text { points }\end{array}$ \\
Number at risk & $\mathbf{0}$ & $\mathbf{5 0 0}$ & $\mathbf{1 0 0 0}$ & $\mathbf{1 5 0 0}$ & $\mathbf{2 0 0 0}$ \\
\cline { 2 - 7 } & 9 & 7 & 4 & 4 & 2 \\
\hline Highest tertile & 10 & 4 & 2 & 2 & 1 \\
Middle tertile & 9 & 3 & 0 & 0 & 0 \\
Lowest tertile & \multicolumn{5}{c}{ Survival days } \\
\hline Data are presented as $\mathrm{n}$. &
\end{tabular}

change in saturation and walk velocity during continuous exertion. The parameters of the TWT are designed to summarise important information about gas exchange and exercise performance, which relate to survival in IPF. For example, end-exercise $\mathrm{Pa}_{1} \mathrm{O}_{2}$ during maximal exercise $[7,12]$ and submaximal steady-state exercise [12] are important measures of disease severity in IPF, leading to the hypothesis in this study that change in saturation during self-paced walking is a meaningful measure of disease status and outcome in IPF. This was also recently illustrated by LAMA et al. [17] who showed that, in a subgroup of patients with IPF without resting hypoxaemia, desaturation to $88 \%$ at any point during the 6MWT was associated with an increased hazard of death; however, the 6MWT distance was not associated with survival.

The TWT has specific criteria to end the test prior to $6 \mathrm{~min}$, with the expectation that many patients with IPF are unable to complete 6 min of continuous exertion [17, 24]. A saturation of $80 \%$ was chosen as one of the stopping criteria in the TWT because of the potential for cardiac arrhythmias and inaccurate pulse oximetry tracings $<80 \%$. The data in the current study confirms that persons with IPF often demonstrate significant desaturation during 6 min of continuous walking, especially in
TABLE 5 Numbers at risk according to the tertiles of the change in saturation parameter at different surviva time points

\begin{tabular}{lccccc} 
Number at risk & \multicolumn{5}{c}{ Survival days } \\
\cline { 2 - 6 } & $\mathbf{0}$ & $\mathbf{5 0 0}$ & $\mathbf{1 0 0 0}$ & $\mathbf{1 5 0 0}$ & $\mathbf{2 0 0 0}$ \\
\hline Lowest tertile & 9 & 7 & 5 & 5 & 5 \\
Middle tertile & 11 & 6 & 1 & 1 & 1 \\
Highest tertile & 8 & 1 & 0 & 0 & 0 \\
\hline
\end{tabular}

Data are presented as $n$.

TABLE 6 Results of univariate logistic regression models relating parameters of the timed walk test and pulmonary function to mortality

\begin{tabular}{|c|c|c|}
\hline Variables & Odds ratio $(95 \% \mathrm{Cl})$ & p-value \\
\hline Resting room air $\mathrm{SP}, \mathrm{O}_{2}$ & $0.78(0.56-1.11)$ & 0.169 \\
\hline End-exercise $\mathrm{SP}, \mathrm{O}_{2} 2 \%$ units & $0.45(0.26-0.81)$ & 0.007 \\
\hline Change in $\mathrm{SP}, \mathrm{O}_{2}$ with exercise $\#$ & $0.67(0.48-0.94)$ & 0.020 \\
\hline Walk distance $30-\mathrm{m}$ units & $0.80(0.68-0.95)$ & 0.012 \\
\hline Walk velocity $0.1-\mathrm{m} \cdot \mathrm{s}^{-1}$ units & $0.67(0.50-0.90)$ & 0.007 \\
\hline DL,co \% pred & $0.83(0.72-0.96)$ & 0.010 \\
\hline FVC \% pred & $1.00(0.96-1.04)$ & 0.996 \\
\hline Resting $\mathrm{Pa}, \mathrm{O}_{2} \mathrm{mmHg}$ & $0.90(0.83-0.99$ & 0.030 \\
\hline Resting $\mathrm{PA}-\mathrm{a}, \mathrm{O}_{2}$ difference $\mathrm{mmHg}$ & $1.05(0.99-1.11)$ & 0.143 \\
\hline
\end{tabular}

$\mathrm{Cl}$ : confidence interval; $\mathrm{SP}, \mathrm{O}_{2}$ : arterial oxygen saturation measured by pulse oximetry; DL,CO: diffusing capacity for carbon monoxide; \% pred: \% predicted; FVC: forced vital capacity; $\mathrm{Pa}, \mathrm{O}_{2}$ : arterial oxygen tension; $\mathrm{PA}-\mathrm{a}, \mathrm{O}_{2}$ : alveolararterial oxygen tension. ${ }^{*}$ : for consistency, change in saturation was entered as a negative change such that a lesser degree of desaturation would be associated with reduced mortality. $1 \mathrm{kPa}=0.133 \mathrm{mmHg}$. 
the absence of supplemental oxygen. The standardised approach to the use of supplemental oxygen enabled the assessment of patients with marked differences in disease severity. The walk-distance parameter of the TWT was more susceptible to the addition of supplemental oxygen than the change in saturation parameter in patients with IPF without resting hypoxaemia. It was found that the change in saturation parameter of the TWT had a better association with survival than the walk-distance parameter in this diverse group of patients with IPF.

Exercise performance is a measurement of functional status that is assessed by the walk velocity in the TWT. Hypoxaemia impairs exercise performance in ILD [18, 19], suggesting that correction of hypoxaemia is necessary to fully assess this parameter. By using a two-tiered test based on baseline saturation, it was possible to correct hypoxaemia, if necessary, and assess the change in saturation parameter within a safe range for each patient. The walk-velocity parameter of the TWT has been used previously in chronic obstructive pulmonary disease (COPD) as a measure of functional status [25], and was a highly repeatable measure in the current study. The reproducibility of the walk-distance parameter of the TWT was similar to the reproducibility of 6MWT distance in COPD [26] and heart failure [27], and the walk-velocity parameter was highly reproducible, despite the addition of oxygen between the two tests in those patients without resting hypoxaemia.

The TWT is a clinically relevant, objective measure of disease severity in IPF. The DL,CO, $P a, O_{2}$ and $P A-a, O_{2}$ difference, which are strongly associated with the walk velocity and end-exercise saturation in this study, reflect the severity of parenchymal abnormalities in IPF and have consistently been associated with clinically important endpoints [7, 8, 12, 28-31]. There was no clear association between the TWT and lung volumes in this study. However, lung volumes are inconsistently associated with survival and other outcome measures in IPF [2, 4], and changes in lung volumes are insensitive to the effect of treatment in clinical trials [10, 32].

Survival is a key outcome measure in IPF. This study demonstrates a strong relationship between a number of parameters of the TWT and survival in persons with IPF. The associations between parameters of the TWT and survival were shown using a proportional-hazard model and corroborated by logistic regression analysis of 2-yr survival. Due to the modest sample size, the current authors were unable to identify additional factors that might alter the associations between parameters of the TWT and mortality. Future studies in larger numbers of patients may be able to adjust for factors, such as sex and age, to refine the relationship between parameters of the TWT and survival. Since the parameters of the TWT are highly interdependent, it is not possible to state which parameter is most predictive. Similar to other recent studies, DL,CO was also associated with survival to a greater degree than lung volumes [33]. Longitudinal changes in measurements of resting physiological variables (composite index, FVC, DL,CO) have been demonstrated to predict survival in IPF [34-36]. In the current study, the survival in the patient population was predicted by the TWT performed at the baseline visit itself. Additional advantages of the TWT over the $D \mathrm{~L}, \mathrm{CO}$ are that it can be conducted in an ambulatory setting and does not involve a breath-holding manoeuvre required for the DL,CO, which may not be tolerated by some patients with advanced IPF.

This study has a few potential limitations, as follows. 1) The study population consisted of a small number of patients with IPF who had progressed despite conventional therapy. 2) The study was conducted at a single tertiary referral centre with expertise in the management of IPF. 3) The TWT was conducted by a single respiratory therapist. 4) The TWT was not conducted at the time of initial diagnosis and was not serially performed during follow-up. 5) The TWT was not compared with other functional measurements, such as the $6 \mathrm{MWT}$ or formal cardiopulmonary exercise test. 6) The treatment regimen subsequent to the TWT was not controlled for in the analysis. Acknowledging that there is no known effective therapy to date, individual therapies are unlikely to have confounded the relationship between the TWT and survival.

In summary, the timed walk test is a clinical tool that can be performed in the ambulatory setting and relates to important aspects of disease severity and long-term outcome in idiopathic pulmonary fibrosis. This simple functional measurement may have a role in the clinical evaluation of persons with idiopathic pulmonary fibrosis, and may serve as a reliable outcome measure to assess treatment response, guide timing of lung transplantation and predict long-term survival in idiopathic pulmonary fibrosis. Future studies comparing the timed walk test with the 6-min walk test and/or other exercise tests with continuous measurements of arterial oxygen saturation measured by pulse oximetry in patients with idiopathic pulmonary fibrosis are indicated to validate the findings of this study in a larger population.

\section{ACKNOWLEDGEMENTS}

The authors are greatly indebted to the patients and their families for participating in this study, and to community physicians for referring their patients to the Interstitial Lung Disease, Sarcoid and Pulmonary Fibrosis Program at the University of Washington Medical Center, Seattle, WA, USA, for further management of idiopathic pulmonary fibrosis and related problems.

\section{REFERENCES}

1 American Thoracic Society. Idiopathic pulmonary fibrosis: diagnosis and treatment. International consensus statement. American Thoracic Society (ATS), and the European Respiratory Society (ERS). Am J Respir Crit Care Med 2000; 161: 646-664.

2 Mapel DW, Hunt WC, Utton R, Baumgartner KB, Samet JM, Coultas DB. Idiopathic pulmonary fibrosis: survival in population based and hospital based cohorts. Thorax 1998; 53: 469-476.

3 Carrington CB, Gaensler EA, Coutu RE, FitzGerald MX, Gupta RG. Natural history and treated course of usual and desquamative interstitial pneumonia. N Engl J Med 1978; 298: 801-809. 
4 Turner-Warwick M, Burrows B, Johnson A. Cryptogenic fibrosing alveolitis: clinical features and their influence on survival. Thorax 1980; 35: 171-180.

5 Hubbard R, Johnston I, Britton J. Survival in patients with cryptogenic fibrosing alveolitis: a population-based cohort study. Chest 1998; 113: 396-400.

6 Tukiainen P, Taskinen E, Holsti P, Korhola O, Valle M. Prognosis of cryptogenic fibrosing alveolitis. Thorax 1983; 38: 349-355.

7 King TE Jr, Schwarz MI, Brown K, et al. Idiopathic pulmonary fibrosis: relationship between histopathologic features and mortality. Am J Respir Crit Care Med 2001; 164: 1025-1032.

8 Schwartz DA, Helmers RA, Galvin JR, et al. Determinants of survival in idiopathic pulmonary fibrosis. Am J Respir Crit Care Med 1994; 149: 450-454.

9 Erbes R, Schaberg T, Loddenkemper R. Lung function tests in patients with idiopathic pulmonary fibrosis. Are they helpful for predicting outcome? Chest 1997; 111: 51-57.

10 Gay SE, Kazerooni EA, Toews GB, et al. Idiopathic pulmonary fibrosis: predicting response to therapy and survival. Am J Respir Crit Care Med 1998; 157: 1063-1072.

11 Nicholson AG, Fulford LG, Colby TV, du Bois RM, Hansell DM, Wells AU. The relationship between individual histologic features and disease progression in idiopathic pulmonary fibrosis. Am J Respir Crit Care Med 2002; 166: 173-177.

12 King TE Jr, Tooze JA, Schwarz MI, Brown KR, Cherniack RM. Predicting survival in idiopathic pulmonary fibrosis: scoring system and survival model. Am J Respir Crit Care Med 2001; 164: 1171-1181.

13 Bittner V, Weiner DH, Yusuf S, et al. Prediction of mortality and morbidity with a 6-minute walk test in patients with left ventricular dysfunction. SOLVD Investigators. JAMA 1993; 270: 1702-1707.

14 Rejeski WJ, Foley KO, Woodard CM, Zaccaro DJ, Berry MJ. Evaluating and understanding performance testing in COPD patients. J Cardiopulm Rehabil 2000; 20: 79-88.

15 McDermott MM, Greenland P, Liu K, et al. The ankle brachial index is associated with leg function and physical activity: the Walking and Leg Circulation Study. Ann Intern Med 2002; 136: 873-883.

16 Brooks D, De Rosie J, Mousseau M, Avendano M, Goldstein RS. Long term follow-up of ventilated patients with thoracic restrictive or neuromuscular disease. Can Respir J 2002; 9: 99-106.

17 Lama VN, Flaherty KR, Toews GB, et al. Prognostic value of desaturation during a 6-minute walk test in idiopathic interstitial pneumonia. Am J Respir Crit Care Med 2003; 168: 1084-1090.

18 Harris-Eze AO, Sridhar G, Clemens RE, Gallagher CG, Marciniuk DD. Oxygen improves maximal exercise performance in interstitial lung disease. Am J Respir Crit Care Med 1994; 150: 1616-1622.

19 Harris-Eze AO, Sridhar G, Clemens RE, Zintel TA, Gallagher CG, Marciniuk DD. Role of hypoxemia and pulmonary mechanics in exercise limitation in interstitial lung disease. Am J Respir Crit Care Med 1996; 154: 994-1001.

20 Raghu G, Mageto YN, Lockhart D, Schmidt RA, Wood DE, Godwin JD. The accuracy of the clinical diagnosis of newonset idiopathic pulmonary fibrosis and other interstitial lung disease: a prospective study. Chest 1999; 116: 1168-1174.

21 American Thoracic Society, European Respiratory Society. American Thoracic Society/European Respiratory Society International Multidisciplinary Consensus Classification of the Idiopathic Interstitial Pneumonias. This joint statement of the American Thoracic Society (ATS), and the European Respiratory Society (ERS) was adopted by the ATS board of directors, June 2001 and by the ERS Executive Committee, June 2001. Am J Respir Crit Care Med 2002; 165: 277-304.

22 Standardization of Spirometry, 1994 Update. American Thoracic Society. Am J Respir Crit Care Med 1995; 152: 1107-1136.

23 Crapo RO, Jensen RL, Hegewald M, Tashkin DP. Arterial blood gas reference values for sea level and an altitude of 1,400 meters. Am J Respir Crit Care Med 1999; 160: 1525-1531.

24 Chetta A, Aiello M, Foresi A, et al. Relationship between outcome measures of six-minute walk test and baseline lung function in patients with interstitial lung disease. Sarcoidosis Vasc Diffuse Lung Dis 2001; 18: 170-175.

25 Menard-Rothe K, Sobush DC, Bousamra M 2nd, Haasler GB, Lipchik RJ. Self-selected walking velocity for functional ambulation in patients with end-stage emphysema. J Cardiopulm Rehabil 1997; 17: 85-91.

26 Sciurba F, Criner GJ, Lee SM, et al. Six-minute walk distance in chronic obstructive pulmonary disease: reproducibility and effect of walking course layout and length. Am J Respir Crit Care Med 2003; 167: 1522-1527.

27 Demers C, McKelvie RS, Negassa A, Yusuf S. Reliability, validity, and responsiveness of the six-minute walk test in patients with heart failure. Am Heart J 2001; 142: 698703.

28 Schwartz DA, Van Fossen DS, Davis CS, et al. Determinants of progression in idiopathic pulmonary fibrosis. Am J Respir Crit Care Med 1994; 149: 444-449.

29 Mogulkoc N, Brutsche MH, Bishop PW, Greaves SM, Horrocks AW, Egan JJ. Pulmonary function in idiopathic pulmonary fibrosis and referral for lung transplantation. Am J Respir Crit Care Med 2001; 164: 103-108.

30 Wells AU, King AD, Rubens MB, Cramer D, du Bois RM, Hansell DM. Lone cryptogenic fibrosing alveolitis: a functional-morphologic correlation based on extent of disease on thin-section computed tomography. Am J Respir Crit Care Med 1997; 155: 1367-1375.

31 Xaubet A, Agusti C, Luburich P, et al. Pulmonary function tests and CT scan in the management of idiopathic pulmonary fibrosis. Am J Respir Crit Care Med 1998; 158: 431-436.

32 Hanson D, Winterbauer RH, Kirtland SH, Wu R. Changes in pulmonary function test results after 1 year of therapy as predictors of survival in patients with idiopathic pulmonary fibrosis. Chest 1995; 108: 305-310.

33 Mogulkoc N, Brutsche MH, Bishop PW, et al. Pulmonary (99m)Tc-DTPA aerosol clearance and survival in usual interstitial pneumonia (UIP). Thorax 2001; 56: 916-923.

34 Latsi PI, du Bois RM, Nicholson AG, et al. Fibrotic idiopathic interstitial pneumonia: the prognostic value of longitudinal functional trends. Am J Respir Crit Care Med 2003; 168: 531-537. 
35 Collard HR, King TE Jr, Bartelson BB, Vourlekis JS, Schwarz MI, Brown KK. Changes in clinical and physiologic variables predict survival in idiopathic pulmonary fibrosis. Am J Respir Crit Care Med 2003; 168: 538-542.
36 Flaherty KR, Mumford JA, Murray S, et al. Prognostic implications of physiologic and radiographic changes in idiopathic interstitial pneumonia. Am J Respir Crit Care Med 2003; 168: 543-548. 